\title{
Maritime container logistics and onshore transportation systems (Part 1)
}

\author{
Ek Peng Chew • Hans-Otto Günther • \\ Kap Hwan Kim · Herbert Kopfer
}

Published online: 28 September 2011

(C) Springer Science+Business Media, LLC 2011

The last decade has seen tremendous investments in new container ports, vessels, and linked onshore transportation systems. Due to the high level of customer service requested and the complexity of logistic processes in seaport container terminals, many terminal operators have attempted to improve the performance of their terminals by applying new technologies including automated equipment, advanced information technologies, and optimization techniques. The demand for these new technologies has been further intensified as the size of deep-sea vessels gets larger and coastal and landside transportation systems are linked to major container ports. As a result, global freight networks are emerging which combine maritime transport, inland waterways and onshore road and rail transportation systems.

The primary objective of this special issue is to reflect the recent developments in maritime and landside container transport and to examine research issues concerned

\footnotetext{
E. P. Chew

Department of Industrial \& Systems Engineering, National University of Singapore, 1 Engineering Drive 2, Singapore, Singapore

e-mail: isecep@nus.edu.sg

H.-O. Günther ( $\bowtie)$

Department of Production Management, Technical University of Berlin, Straße des 17. Juni 135, 10623 Berlin, Germany

e-mail: hans-otto.guenther@tu-berlin.de

K. H. Kim

Department of Industrial Engineering, Pusan National University, 30 Changjeon-Dong,

Kumjeong-Ku, Busan 609-735, Korea

e-mail: kapkim@pusan.ac.kr

H. Kopfer

Department of Logistics, University of Bremen, Wilhelm-Herbst-Straße 5, 28359 Bremen, Germany e-mail: kopfer@uni-bremen.de
} 
with quantitative analysis and decision support for container terminal logistics and freight transportation systems. For the first part of the special issue three papers have been selected for publication after a thorough peer-review according to the standards of the FSM journal. The following additional accepted papers are available for download from the publisher's webpage at http://www.springerlink. com/content/1936-6590 and will appear in the second and third part of the special issue in due course.

- Hendriks, M.P.M., Armbruster, D., Laumanns, M., Lefeber, E., Udding, J.T.: Strategic allocation of cyclically calling vessels for multi-terminal container operators

- van Asperen, E., Borgman, B., Dekker, R.: Evaluating impact of truck announcements on container stacking efficiency

- Blander Reinhardt, L., Pisinger, D.: A branch and cut algorithm for the container shipping network design problem

- Caris, A., Macharis, C., Janssens, G.K.: Corridor network design in hinterland transportation systems

- Lee, C.-Y., Yu, M.: Inbound container storage price competition between the container terminal and a remote container yard

- Kim, J., Morrison, J.R.: Offshore port service concepts: classification and economic feasibility

\section{Papers in Part 1 of the special issue}

The first paper by A.-D. Do Ngoc and I.-K. Moon addresses the capacity expansion problem for container terminals. Due to the imbalance of the global container flows shipping companies must frequently decide on the repositioning and the lease and purchase of empty containers. To solve the related decision problem the authors formulate a mixed integer linear optimization model and develop a heuristic algorithm based on Lagrangian relaxation. Computational experiments show the efficiency of the proposed algorithm.

The subsequent paper by A.M. Douma, P.C. Schuur and J.M.J. Schutten presents a practical approach for the alignment of barge and terminal operations in a port considering restricted opening times of terminals, unbalanced networks, the presence of sea vessels, and closing times of containers. The performance of the proposed Multi-Agent system is evaluated by means of a comprehensive simulation study. It is shown that the system enables barge and terminal operators to align their operations efficiently.

The final paper in the first part of the special issue by $S$. Wang, T. Wang and $Q$. Meng contains a note on liner ship fleet deployment, i.e. the assignment of ships to liner service routes for delivering containers in a planning horizon. Various reformulations of optimization models known from the literature are proposed. A computational study demonstrates efficiency improvement of the reformulated model. 


\section{Concluding remarks}

This special issue has greatly benefited from the cooperation among the authors, reviewers, and editors. We would like to express our sincere thanks to the reviewers for their excellent and timely refereeing. Last, but not least, we thank all authors for their contributions which made this special issue possible. 